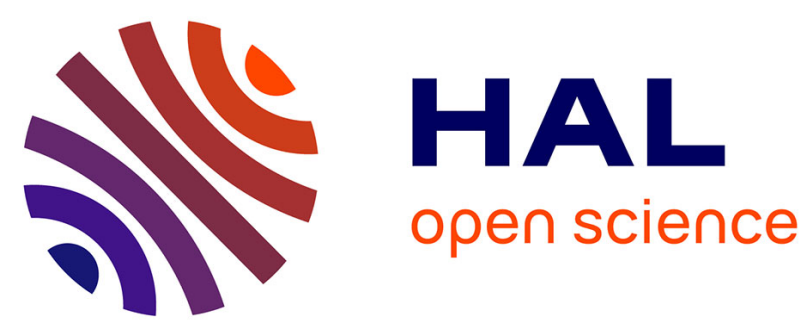

\title{
Adapting the available water capacity indicator to forest soils: An example from the Haut-Languedoc (France)
}

\author{
Baptiste Algayer, Philippe Lagacherie, Jean Lemaire
}

\section{To cite this version:}

Baptiste Algayer, Philippe Lagacherie, Jean Lemaire. Adapting the available water capacity indicator to forest soils: An example from the Haut-Languedoc (France). Geoderma, 2020, 357, 10.1016/j.geoderma.2019.113962 . hal-02623221

\section{HAL Id: hal-02623221 \\ https://hal.inrae.fr/hal-02623221}

Submitted on 9 Sep 2021

HAL is a multi-disciplinary open access archive for the deposit and dissemination of scientific research documents, whether they are published or not. The documents may come from teaching and research institutions in France or abroad, or from public or private research centers.
L'archive ouverte pluridisciplinaire HAL, est destinée au dépôt et à la diffusion de documents scientifiques de niveau recherche, publiés ou non, émanant des établissements d'enseignement et de recherche français ou étrangers, des laboratoires publics ou privés.

\section{(ㅇ)(1) $\$$}

Distributed under a Creative Commons Attribution - NonCommercial - NoDerivatives $\mid 4.0$ 


\section{Confronting the available water content indicator to forest soils: the example}

\section{2 from the Haut-Languedoc (France).}

3 Algayer Baptiste ${ }^{1}$, Lagacherie Philippe ${ }^{2}$, Lemaire Jean ${ }^{3}$

$4{ }^{1}$ Parc naturel régional du Haut-Languedoc, 1 place du Foirail, BP9, 34220 Saint-Pons de 5 Thomières.

6 '2LISAH, Université de Montpellier, IRD, INRA, Montpellier SupAgro, place Viala, 34060

7 Montpellier.

$8 \quad{ }^{3}$ Institut pour le Développement Forestier, 175 cours Lafayette, 69006 Lyon.

Highlight:

- The soil available water content (SAWC) calculation needs specific adjustments when applied to forest soils.

- $\quad$ The considered soil volume is the main driver of SAWC

- The soil coarse fraction contains available water for plant, and this amount of water must be considered in soil available water content assessment.

- Specific pedotransfert functions are needed for the fine earth water retention assessment of forest soils.

\section{Abstract:}

Soil available water content (SAWC) is becoming a crucial issue for forest management in the context of climate changes. Nevertheless, SAWC indicator which was created for agricultural soils needs specific adaptations when it is estimated for forest soils. This study aimed to find the best way to apply the SAWC indicator with regard to its significance for explaining variations of tree fertility across a given region. An extensive study over a spatial sampling of 
100 Douglas-fir stand plots was conducted in the Haut Languedoc Regional Nature Parc (Southern France). It involved stand fertility assessments, morphological observations of deep soil pits including the saprolite, quantitative estimations of coarse fragments, texture and organic matter laboratory analysis and water retention and density measurements on a limited sample of horizons (35). Different SAWC were computed from the collected data. They differed in the methods i) for estimating the fine earth water retention - national vs local pedotransfer function -, ii) for dealing with the coarse fragments - assumed to contribute or not to the water retention of soils- and iii) for estimating the soil volumes - variable thicknesses and considerations of rooting. The results showed that the SAWC that explained the best the variations of tree fertilities over the study area ( $21 \%$ of the variance) was obtained by fine earth water retention estimated from a local pedotransfert function, by considering the water retention of the coarse fraction and by exploring the largest volumes (thicknesses of $200 \mathrm{~cm}, 300 \mathrm{~cm}$ and equal to the depth to bedrock) without explicit consideration of the rooting observations. The ranking of SAWC component impact on SAWC values was i) soil volume, ii) coarse fraction water retention and iii) fine earth retention. Those results revealed that improvements in estimating coarse fraction water retention and soil volumes, and, to a lesser extent, in estimating fine-earth water retention by forest soil adapted pedotransfer function, would greatly benefit to the application of the SAWC indicator to forest soils.

Keywords: soil available water capacity, forest soils, Douglas-fir, rock fragment water retention, pédotransfert function.

\section{Introduction}

Soil available water capacity (SAWC) is a well-known concept that have been used for a long time for expressing the capacity of soils to store water for plants (Veihmayer and Hendrickson, 1927). It has been demonstrated that SAWC is one of the most important soil factors for plant 
growth, influencing photosynthesis rate, carbon allocation, and nutrient cycling (Lebourgeois et al., 2005; Breda et al., 2006). It is therefore a first order parameter that is used in land evaluations and recently in soil ecosystem service assessment (Dominati et al. 2014). For now, in the literature, SAWC is expressed as follows (equation 1) (Cousin et al., 2003):

$$
S A W C=\sum_{H i} \operatorname{Thickness}_{(H i)} \times\left[\left(W_{(F C)-} W_{(W p)}\right) \times D\right]_{(H i)} \times \frac{100-C F}{C F}
$$

53

54

Where $\mathrm{Hi}$ is the horizon $\mathrm{i}$ of the soil profile, Thickness ${ }_{(H i)}$ is the horizon thickness in centimeters, $W_{(F C)}$ is the gravimetric water content at the field capacity for fine earth of the horizon, $W_{(W p)}$ is the gravimetric water content at the wilting point for fine earth of the horizon, $D$ is the bulk density of the fine earth of the horizon, CF is volume of the coarse fraction of the horizon in percentage. This equation can be divided in three components: i) the fine earth water retention properties that is usually estimated by pedotranfert functions (PTF) (Wösten et al., 2001; Bruand et al., 2003; Almajou et al., 2008) ii) the coarse fraction volume, that is usually excluded from the equation considering that coarse fragments do not contain available water and iii) the thickness of the material that weights the AWC of each horizon through the soil profile.

SAWC concept has been created for crop field soils, but is also largely applied to forest soils (Curt et al., 2001; Chen et al., 2002; Seynave et al., 2005; Piedallu et al., 2011). SAWC is commonly used in combination with climatic and topographic data in order to predict site fertility of a forest stand (Chen et al., 2002; Seynave et al., 2005). It is also used for soil water balance calculation (Granier et al., 1999) in order to study the forest-stand response to drought that is becoming a crucial issue in context of climate changes (Breda et al., 2006; Sergent et al., 2012; Littke et al., 2018). 
However, applying SAWC indicator to forest soils carries some difficulties related with the specificities of forest soil and forest context. Firstly, trees are powerful plants whose roots may colonize a greater soil thickness than cultivated plant. Many studies showed that colonization by roots could go far beyond the soil, reaching the saprolite zone in which this colonization can be very irregular (Curt et al., 1998; Graham et al., 2010; Brantley et al., 2017). This makes not straightforward to define in equation 1 an appropriate value of thickness that account for this heterogeneity. Second, by reaching the saprolite zone, forest soils often show high coarse fraction volumes. It has been demonstrated that coarse fragment can store water which could be available for plant (Flint and Childs, 1984; Tetegan et al. 2011; Parajuli et al., 2017). When the proportion of coarse fragment becomes important, this could play a major role in SAWC. Hence, equation 1 should be modified for taking into account the AWC of the coarse fraction $\left(A W C_{(C F)}\right)$. Lastly, the determination of the fine earth $A W C\left(A W C_{(F E)}\right)$ has been by far much more investigated than the two previously evoked components. To cope with metrologic difficulties in measuring gravimetric water content at field capacity $\left(\mathrm{W}_{(\mathrm{FC})}\right)$ and at wilting point $\left(\mathrm{W}_{(\mathrm{WP})}\right)$ there is a wide use of pedotransfer functions (PTF) (Jamagne et al., 1977; Wösten et al., 2001; Almajou et al., 2008). However, most of these PTF have been developed from agricultural soil measurements and to our knowledge, no specific PTF for forest soils exists (Vincke and Delvaux, 2005; Piedallu et al., 2011). Piedallu et al (2018) promoted the use of Almajou 2008' PTF which is derived from agricultural soils. The applicability of PTF to forest soil remains unknown.

In this paper, we apply the concept of SAWC for characterizing the potential of growth of Douglas-fir in the Haut Languedoc Regional Nature Parc (Southern France). Different modalities for calculating the SAWC components are applied from a dataset of 100 deep soil 
pits. The resulting SAWCS are evaluated with regard to their correlation with an indicator of tree growth.

\section{The study area and data}

\subsection{General description}

The Haut Languedoc Regional Nature Park is a 314000 hectares area located in the south of France. This area is covered at $66 \%$ by forest, making wood production a crucial issue for the region. The studied area lays through the confluence zone of three contrasted climates. At the east, Mediterranean climate present an annual rainfall of $650 \mathrm{~mm}$, concentrated during autumn and spring seasons, and is characterized by a high summer water deficit $(-300 \mathrm{~mm})$. In the west, oceanic climate is more humid $(1650 \mathrm{~mm}$ annual rainfall) with a more uniform rainfall regime and a lower summer water deficit $(-100 \mathrm{~mm})$. Finally, in the north, a semimountain climate shows wetter and colder average conditions. Geology and topography are also very heterogeneous. The south-west of the study area, called black mountain, is composed on granitic and gneissic mountains reaching 1200 meters high. The center of the area is composed on granitic and gneissic plateau ranging between 800 and 1100 meters high, surrounded by schist and calcschist hills in the north west and schist and calcareous materials in the south east. Such peripheric regions show lower altitude but very rugged terrain with deep valleys and narrows crests. Such variability implies very heterogeneous forest soil type distribution and thus, a large range of SAWC.

\subsection{Plot sampling}

A 100 plots sampling design was set up in order to exhaustively represent forest soils of the studied area. The sampling design was performed on Douglas-Fir (Pseudotsuga menziesii) plantations because this species is of high economic interest and is therefore widely represented across the different climates and parent materials of the study area, which 
ensures to get a large range of soil conditions. Sampling strategy was based on the

118

119

120

121

122

123

124

125

126

127

128

129

130

131

132

combination of climatic, geologic, and topographic classifications. Three sub-zones were distinguished: the central mountain zone (mountain climate), the western zone (oceanic climate) and the eastern zone (Mediterranean climate). Topography classification included four topographic positions: plateau, top slope, mid slope and lower slope combined with three exposition modalities (north, south and other). In the central zone, classification was based on topographic conditions combined with an altitude threshold (800 meters). For the western and eastern zones, topographic classification was combined with geologic classification: schist and granites rocks in the western zone, schist and calcareous rocks in the eastern zone. Sampling strategy also took into account practical conditions such as accessibility for a 25 tons shovel, optimization of the shovel transport, and forest owner agreement.

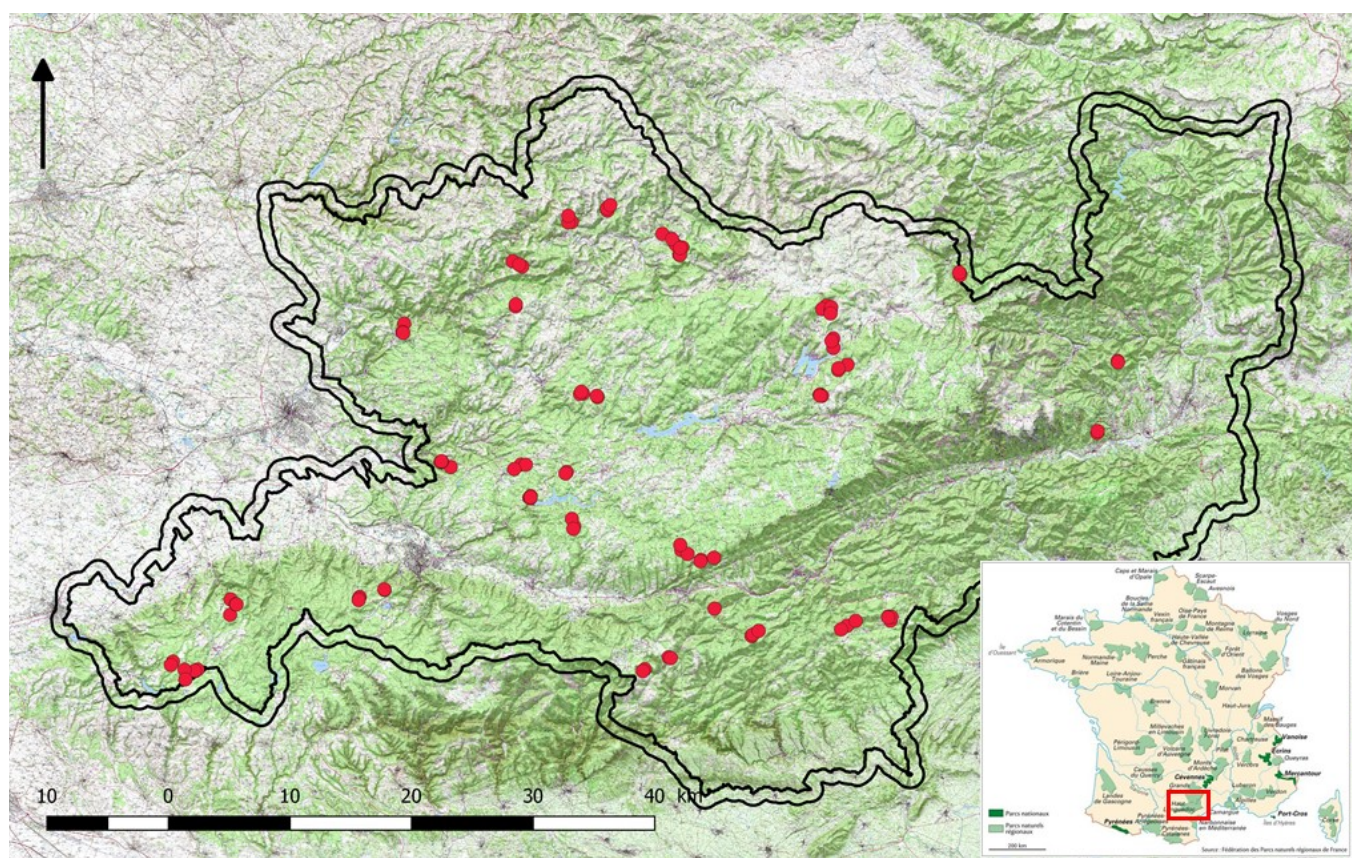

Figure 1: spatial distribution of the sampling plots in the studied area

\subsection{Soil observations}

For each plot, a soil pit was dug using a 25 tons shovel. The soil pit was positioned at a two meters distance from the tree localised at the centre of the trees spiral composing the plot. 
133 Soil material was excavated until the inscrutable bedrock was reached. When bedrock was

134 too deep underground, the soil pit limit was 4.5 meters depth, corresponding on the maximum

135 accessible depth for the shovel mechanical arm. Soil profiles were visually described following

136 the French protocol of soil description (Infosol, 2018), including the measurement of the soil

137 horizons thickness. Sometimes the soil horizons presented a complex geometry i.e. non-

138 horizontal horizon limits, discontinuous, or enclosed horizons, into the saprolite zone. Non-

139 horizontal horizon limits were registered using the DONSOL protocol. Discontinuous and

140 enclosed horizons were considered as component of a complex horizons, which required to

141 modify the description protocol. Furthermore, graphical representations of each profiles were

142 performed to memorize the observed horizon complexity.

143 A particular attention was paid for characterizing coarse fraction, both quantitatively and

144 qualitatively. The classical estimation of the amount of coarse fragment from a visual

145 interpretation of the profile was replaced by a more precise technique that estimated

146 separately the gravel fraction (between $2 \mathrm{~mm}$ and $2 \mathrm{~cm}$ diameter) and the pebbles fraction

147 (more than $2 \mathrm{~cm}$ ). The latter was determined in the field by a $2 \mathrm{~cm}$ sieving and weighing. The

148 determined fine earth and pebble densities were used to convert mass fraction into

149 volumetric fractions. The gravel fraction was determined in the laboratory from the $2 \mathrm{~cm}$ -

150 sieved samples obtained from the previously evoked operation. The total coarse fraction was

151 obtained by adding the two previously determined fractions.

152 A total of 80 rock fragments were sampled for density and water retention measurement. The

153 sampling considered eight rock fragment types that corresponded to the mainly represented

154 lithologic classes of the studied area: mica-schist, black schist, shale, pelitic sandstone, banded

155 sandstone, dolomite, limestone, granite and gneiss. Ten samples of each lithologic class were

156 collected. The rock samples consisted of flat-shaped pebbles with a size varying between $3 \mathrm{~cm}$ 
and $6 \mathrm{~cm}$ for the longer diameter. The samples were gently brushed prior measurement, in order to remove their fine earth coatings.

159 Considering the fine earth, 200 grams samples were collected from each soil horizon in order to measure five class particle size distribution and organic matter content. In addition, 161 undisturbed clods were sampled from 35 horizons ( $A$ and $S$ horizons), for water retention measurements. The sampled clods were chosen in order to exhaustively represent the soil types of the studied area. The undisturbed clods were gently fragmented by hand in order to form $5 \mathrm{~cm}$ diameter clods. The samples were kept in plastic boxes and stored at $4^{\circ} \mathrm{C}$ until analyses.

2.4. Water retention and dry bulk density measurements

Rock fragments and clods gravimetric water content was determined at field capacity (-330 $\mathrm{hPa})\left(\mathrm{W}_{(\mathrm{FC})}\right)$ and at wilting point $(-15000 \mathrm{hPa})\left(\mathrm{W}_{(\mathrm{WP})}\right)$ following a classical protocol (ref). Measurements were performed on a pressure membrane. After saturation by capillarity,

170 samples were placed on a paste of saturated kaolinite to obtain a sufficient hydraulic 171 continuity with the pressure membrane. After one week of equilibrium in pressure cells, the 172 gravimetric water content was measured.

173 Dry bulk density was estimated using the paraffin method (ref). Samples were dipped into 174 hot paraffin. By cooling, a thin paraffin coating was formed and blocked the sample pores. 175 Paraffin coated-samples were dipped into a water container, and the coated sample volume 176 was estimated by the water displacement. Finally, the paraffin coating was carefully removed 177 from the sample using a cutter. Paraffin residues were weighed and the volume of the coating 178 was calculated. The rock fragment bulk density was calculated by the difference between the coated sample volume and the paraffin volume. The measurement of bulk density, gravimetric 
water content at field capacity and wilting point were repeated and averaged on 10 different

181 samples for each fine earth horizon, and each rock fragment lithologic class.

182 Following the measurements, both fine earth and coarse fragment water retention properties 183 were calculated and summed up into an AWC coefficient (AWCcoef) calculated using the 184 following equation 3.

$$
A W C \text { coef }=\left(W_{(F C)}-W_{(W p)}\right) * D * 0.1
$$

185 Where $\mathrm{W}_{(\mathrm{FC})}$ is the gravimetric water content at field capacity in $\mathrm{mm}, \mathrm{W}_{(\mathrm{WP})}$ is the gravimetric 186 water content at the wilting point in $\mathrm{mm}$ and $\mathrm{D}$ is the bulk density.

187 Coarse fraction AWC coefficient $\left(A W C C_{C o e f}(C F)\right)$ was calculated for the eight considered 188 lithologic classes. Fine earth AWC coefficient was calculated for the 35 sampled horizons $189\left(\right.$ AWCCOef $\left._{(F E)}\right)$.

\subsection{Root measurements}

191 For each soil profile, the depth of the deepest visible root was measured. At the horizon scale, root density was estimated by counting. For each horizon, three $10 * 10 \mathrm{~cm}$ squares areas were considered. The first square was localized on the highest root density zone of the horizon, the second square on the lowest density zone and the third was localized on the medium root density zone. For each square, visible roots with a diameter less than $2 \mathrm{~cm}$, were counted and 196 classified by health status (healthy, dead).

197 2.6. Site fertility Index H50

198 A forest stand plot consisted of a 20 dominant trees spiral. Each diameter at breast height $199(1.30 \mathrm{~m})$ was measured. The dominant height of the three largest trees was measured using 200 a Vertex laser dendrometer. The age was measured using a Pressler increment borer. Site 201 fertility index was calculated for each stand at the reference age of 50 years $\left(\mathrm{H}_{(50)}\right)$ using the 202 model by Angelier (2006). 


\section{SAWC calculations}

204

SAWC was determined for each of the 100 soil profiles from the collected data. We present in the following the different modalities that were considered for determining each SAWC components and further the combinations of modalities used to determine different possible SAWC for a given soil profile.

\subsection{Fine earth horizon AWC}

Fine earth horizon AWC was determined for each horizon by two different methods. The first was the class PTF from Al Majou (2008) that was recently recommended as the best one for application in forest soil (Piedallu et al., 2018). Considering this method, AWCcoef $(\mathrm{FE})$ was attributed to each horizon in function of the textural class measured in the laboratory and the soil horizon type (Al Majou, 2008). The second method used a local continue PTF that was computed from the 35 -clods dataset. A linear regression was performed to predict the measured $A W C$ coef $(F E)$ or its calculation parameters $\left(\mathrm{W}_{(\mathrm{FC})}, \mathrm{W}_{(\mathrm{WP})}\right.$ and $\left.D\right)$ by using simple soil properties as explanatory factors (sand, silt, clay and organic matter amount). The best model among all the tested combinations predicted $\mathrm{AWCCOef}_{(\mathrm{FE})}$ by the following equation 4.

$$
\operatorname{LocalAWCcoef}_{(F E)}=[(36,4934+\text { Sand } *-0,1055)-(15,752+O M * 0,7095)] * 0.1
$$

\section{Determination coefficient $R^{2}=0.23 ; n=35$}

Where $\mathrm{W}(\mathrm{FC})$ is the volumetric water content at field capacity, $\mathrm{W}(\mathrm{WP})$ is the volumetric water content at wilting point, Sand is the sand content in \% and OM is the organic matter content in \%. Considering this method, LocalAWCCoef $(\mathrm{FE})$, was calculated for each horizon.

\subsection{Coarse fragment horizon AWC}

Two different modalities for dealing with coarse fragment in the calculation of SAWC were considered. The first was the usual one that calculates SAWC without integrating coarse fraction AWC (equation 1). Such approach, comes to assume that the coarse fraction cannot 
store available water for plant. $\mathrm{AWC} \mathrm{Ceef}_{(\mathrm{CF})}$ is then equal to zero, and only fine earth fraction

227 AWC is taken into account. The results of SAWC calculation that followed this modality were

228 further denoted as $\mathrm{SAWC}_{(\mathrm{FE})}$. The second assumes an effective contribution of the coarse

229 fraction to the SAWC. For such method, AWC Coef $_{(\mathrm{CF})}$ was attributed to each horizon depending 230 on the coarse fraction lithology. The results of SAWC calculation that followed this modality 231 were further denoted as $\mathrm{SAWC}_{\text {(total). }}$

$232 \quad 3.3$. Soil profile thicknesses

233 The previously mentioned equation 1 represents the contribution of soil volume in SAWC by 234 a value of thickness, which implicitly supposes that the horizons are perfectly horizontal. Thus, 235 the horizons presenting a complex geometry must be converted into an "equivalent 236 horizontal" horizon thickness, calculated as follows (equation 5).

$$
\text { Equivalent horizon Thickness }=\frac{\operatorname{Vol}_{(h)}}{100} \times \text { Thickness }_{(\text {prof })}
$$

237 Were soil thickness is expressed in $\mathrm{mm}$; $\mathrm{Vol}(\mathrm{h})$ is the complex horizon volume in \%; 238 Thickness $_{(\text {prof })}$ is the thickness of the soil profile in $\mathrm{mm}$.

SAWC was computed for different soil volumes. First, the whole soil profile volume was

240 considered. This comes to define the soil thickness (i.e. the sum of horizon thicknesses in 241 equation 1) as the distance from the soil surface to the inscrutable bedrock without 242 consideration of the rooting $\left(\mathrm{SAWC}_{(\text {Bedrock) }}\right)$. If the bedrock was too deep, the thickness limit 243 was 4.5 meters. Secondly, soil volume consisted to limit the soil thickness to an arbitrary fixed 244 value that define the maximal rooting depth beyond which the tree is not supposed to extract 245 water. Soil thicknesses of $300 \mathrm{~cm}, 200 \mathrm{~cm}, 100 \mathrm{~cm}$ and $50 \mathrm{~cm}$ were considered (SAWC(300), $246 \operatorname{SAWC}_{(200)}, \mathrm{SAWC}_{(100)}$, and $\left.\mathrm{SAWC}_{(50)}\right)$. By the same, a fixed floor corresponding to the depth of

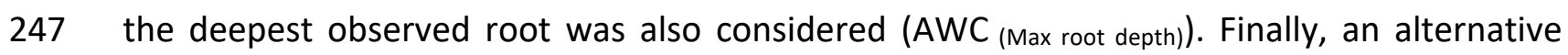


248 method for taking into account more precisely the tree root dispersion was considered.

249 Instead of modifying the value of soil thickness, a roots density index was introduced in the

250 AWC calculation of each horizon. This index was based on a classification derived from Baize

251 and Jabiol (1995) presented in table 1. The mean root density used as input for this

252 classification were calculated from the root observations performed across the 100 soil

253 profiles.

254 Table 1: classification of the root density at the horizon scale

\begin{tabular}{ccccc} 
Mean root density & Minimum root & Medium & Maximum root & Root density \\
(3 squares) & density & root density & density & index \\
\hline$>16 / \mathrm{dm}^{2}$ & - & - & - & 1 \\
\hline$>8 / \mathrm{dm}^{2}$ and $<16 /$ & $>1$ & - & - & 1 \\
$\mathrm{dm}^{2}$ & 0 & - & - & 0.75 \\
\hline$>0 / \mathrm{dm}^{2}$ and $<8 / \mathrm{dm}^{2}$ & 0 & $>1$ & - & 0.75 \\
& 0 & 0 & $>5$ & 0.5 \\
\hline $0 / \mathrm{dm}^{2}$ & 0 & 0 & $<5$ & 0.25 \\
\hline & 0 & 0 & 0 & 0
\end{tabular}

3.4. The different considered SAWC

257 The different modalities for determining the three components of SAWC were combined to

258 produce 28 estimations of SAWC, i.e. two different fine earth approaches ("Almajou2008" PTF

259 and "local" PTF) $x$ two different coarse fraction approaches $\left(\mathrm{SAWC}_{(\mathrm{Total})}, \mathrm{SAWC}_{(\mathrm{FE})}\right) \times$ seven

260 different soil volumes (Table 2).

261 Table 2: description of the soil volumes considered for SAWC calculation 
Name Soil volume

$\mathrm{AWC}_{\text {(Bedrock) }} \quad$ From soil surface to the inscrutable bedrock

If Bedrock was too deep, the depth limit was 4.5 meters

$A W C_{(300)} A W C_{(200)}$, from the surface to a fixed floor depth.

$\mathrm{AWC}_{(100)}, \mathrm{AWC}_{(50)} \quad 300 \mathrm{~cm} ; 200 \mathrm{~cm} ; 100 \mathrm{~cm} ; 50 \mathrm{~cm}$

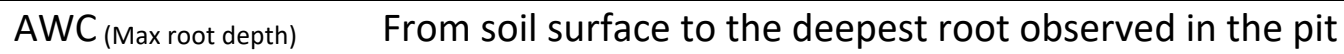

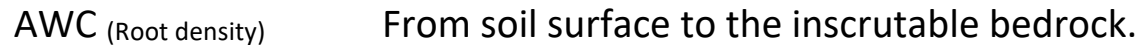

AWC weighted by the horizons root density index

262

263

4. Results

4.1 Basic soil characteristics: average values and variability across the region

Table 3 presents the statistics of the main soil properties that influence SAWC. With a mean

266 of $254 \mathrm{~mm}$, and exceeding 400 centimeters for some plots, the soil thickness reached

267 frequently the saprolite horizon. The studied soils showed high coarse fragments content

268 (55\% at the scale of the soil profile) mainly concentrated in the saprolite horizons. The soil

269 textures were weakly variable across the study area. Most of the profiles were classified as

270 sandy loams, with high sands content resulting from the weathering of granite, gneiss,

271 sandstones and schists. Finally, soil was also characterized by an high organic matter content

272 in the surface horizons (mean $=6.0 \%$ ) that remain non negligible in S horizons (mean $=2.7 \%$ ).

273 Table 3: soil thickness, rock fragment content, clay content, silt content, sand content and

274 organic matter content for the different soil layers of the data set.

$\begin{array}{clllll}\text { Thickness } & \text { \%Coarse } & \text { Clay\% } & \text { Silt\% } & \text { Sand\% } & \text { OM\% } \\ (\mathrm{mm}) & \text { fraction } & & & \\ \end{array}$




\begin{tabular}{lcccccccccccc} 
& mean & sd & mean & sd & mean & sd & mean & sd & mean & sd & mean & sd \\
\cline { 2 - 12 } & & & & & & & & & & & & \\
Profile & $\mathbf{2 5 4 . 0}$ & $\mathbf{1 0 7 . 0}$ & $\mathbf{5 5 . 5}$ & $\mathbf{2 0 . 0}$ & $\mathbf{1 0 . 3}$ & $\mathbf{6 . 8}$ & $\mathbf{2 9 . 3}$ & $\mathbf{1 0 . 6}$ & $\mathbf{5 7 . 3}$ & $\mathbf{1 5 . 7}$ & $\mathbf{1 . 1}$ & $\mathbf{1 . 0}$ \\
Pedolit & $\mathbf{6 7 . 1}$ & $\mathbf{2 9 . 0}$ & $\mathbf{2 1 . 0}$ & $\mathbf{1 6}$ & $\mathbf{1 2 . 9}$ & $\mathbf{6 . 6}$ & $\mathbf{3 2 . 1}$ & $\mathbf{1 1 . 1}$ & $\mathbf{5 1 . 0}$ & $\mathbf{1 4 . 7}$ & $\mathbf{4 . 7}$ & $\mathbf{1 . 9}$ \\
\hline A horizon & 26.2 & 9.0 & 15.0 & 4.0 & 15.7 & 6.3 & 32.7 & 10.3 & 51.6 & 14.7 & 6.0 & 1.8 \\
S horizon & 36.9 & 21.2 & 27.0 & 22.0 & 11.0 & 7.7 & 33.6 & 13.7 & 55.4 & 18.0 & 2.7 & 1.2 \\
\hline Saprolit & $\mathbf{1 8 5 . 4}$ & $\mathbf{1 0 1 . 0}$ & $\mathbf{7 0 . 9}$ & $\mathbf{2 2}$ & $\mathbf{9 . 2}$ & $\mathbf{7 . 4}$ & $\mathbf{2 7 . 9}$ & $\mathbf{1 1 . 2}$ & $\mathbf{6 0 . 1}$ & $\mathbf{1 7 . 4}$ & $\mathbf{0 . 4}$ & $\mathbf{0 . 3}$
\end{tabular}

275

277 Considering the 35 fine-earth clods used for the hydric property measurements, the $278 A W C \operatorname{ACoef} f_{(\mathrm{FE})}$ calculated from the measured parameters $\left(\mathrm{W}_{(\mathrm{FC})}, \mathrm{W}_{(\mathrm{WP})}\right.$ and $\left.D\right)$ and the $279 A W C \operatorname{Aoef}(\mathrm{FE})$ estimated by Almajou PTF showed significant correlations but low coefficient of 280 determination $\left(r^{2}=0.14\right)$. Both $A W C \operatorname{coef}(\mathrm{FE})$ varied into similar ranges, and did not showed 281 significant differences. The $A W C \operatorname{Coef}(\mathrm{FE})$ estimated from the local PTF was significantly and 282 positively correlated with the $A W C \operatorname{coef} f_{(\mathrm{FE})}$ calculated from the measured hydric properties $283\left(r^{2}=0.23\right)$ (Figure 2$)$.
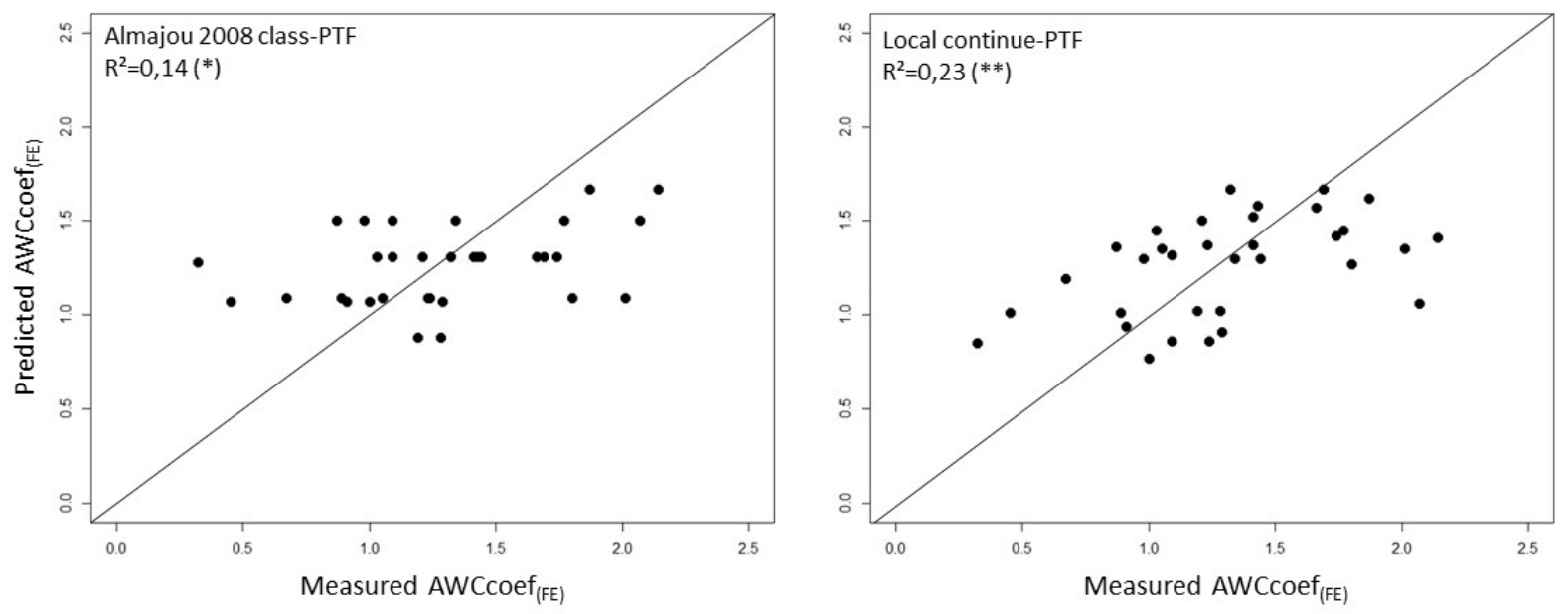

284

Figure 2: determination coefficients $\left(R^{2}\right)$ between $A W C \operatorname{Coef}(\mathrm{FE})$ measured and predicted using 
$A W C \operatorname{coe} f_{(\mathrm{FE})}$ were estimated for each horizon of the 100 soils profiles using both local PTF and

288

289

290

291

292

293

294

295

296

297

298

299

300

Almajou PTF. For A horizons, the $A W C \operatorname{coef}(\mathrm{FE})$ estimated by the local PTF were significantly

higher than the $A W C \operatorname{coef} f_{(\mathrm{FE})}$ estimated by Almajou PTF. The deeper horizons showed opposite results: the $A W C \operatorname{coef} f_{(\mathrm{FE})}$ estimated by local PTF showed significant lower values than those estimated with Almajou PTF.

4.3 Water retention of the coarse fragments

Results of the rock fragments hydric properties measurement showed that the samples contained available water for the trees (table 4). The $A W C \operatorname{coef}(\mathrm{CF})$ varied with the lithology class of the rock fragment, with a minimum coefficient for the black schist and a maximum coefficient for the shale. Granit, gneiss and mica-schist fragments which are the main lithologic class of the studied area showed respectively $A W C$ Coef(CF) of $0.58,0.46$ and 0.67 .

Table 4: Bulck density (D), gravimetric water content at field capacity $\left(W_{(F C)}\right)$ and Wilting point $\left(\left(W_{(W P}\right)\right)$, and the calculated available water capacity coefficient for coarse fraction (AWCcoef(CF) for each lithologic class. $N=10 . s d=$ standard deviation

\begin{tabular}{lcccccccc} 
Lithologic class & Geologic period & $\mathbf{D}$ & $s d$ & $W_{(F C)} \%$ & $s d$ & $W_{(W P)} \%$ & sd & AWCcoef(CF) \\
\cline { 3 - 8 } Mica-schist & Cambro-Ordovician & 2,09 & 0,13 & 5,55 & 0,76 & 2,33 & 0,47 & $\mathbf{0 , 6 7}$ \\
Pelitic sandstone & Lower Cambrian & 2,19 & 0,11 & 6,03 & 2,74 & 2,74 & 1,36 & $\mathbf{0 , 7 2}$ \\
Banded sandstone & Lower Cambrian & 1,87 & 0,04 & 10,9 & 0,46 & 9,3 & 0,28 & $\mathbf{0 , 3 0}$ \\
Black schist & Lower Cambrian & 2,19 & 0,08 & 4,44 & 0,46 & 3,96 & 0,35 & $\mathbf{0 , 1 1}$ \\
Shale & Lower Cambrian & 1,74 & 0,11 & 11,58 & 3,51 & 4,63 & 0,86 & $\mathbf{1 , 2 1}$ \\
Dolomite & Lower Cambrian & 2,13 & 0,07 & 3,86 & 1,27 & 2,82 & 0,96 & $\mathbf{0 , 2 2}$ \\
Granite & Westphalian & 2,27 & 0,09 & 4,26 & 0,59 & 1,7 & 0,54 & $\mathbf{0 , 5 8}$ \\
Gneiss & Cambrian & 1,93 & 0,2 & 5,78 & 2,01 & 3,39 & 0,78 & $\mathbf{0 , 4 6}$ \\
\hline
\end{tabular}


Table 5 shows the SAWC values calculated for the seven mentioned soil volumes, and

304 following the different approaches for coarse fraction and fine earth fraction. Table 6 shows the results of the student tests assessing the effect of the coarse fraction and fine earth fraction approaches.

$A W C_{(\text {Bedrock) }}$ showed the highest SAWC values with a mean of $227.6 \mathrm{~mm}$ and a maximum value reaching 547.0mm (Table 5). SAWC decreased gradually while decreasing the fixed floor

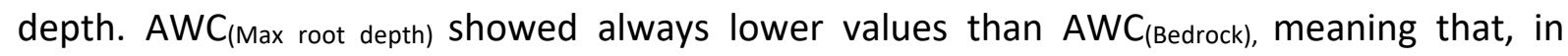
average, the roots maximum depth did not reached the bedrock depth. $A W C_{\text {(Root density) }}$ showed mean values $34 \%$ to $45 \%$ lower than $\mathrm{AWC}_{\text {(Bedrock). }}$ SAWC calculated by integrating the coarse fraction $A W C\left(A W C_{(\text {Total) }}\right)$ showed significant different values than $A W C$ calculated by excluding the coarse fraction $\mathrm{AWC}\left(\mathrm{AWC}_{(\mathrm{FE})}\right)$, whatever the considered soil volume (Table 6). $A W C_{(T o t a l)}$ was always higher than $A W C_{(F E)}\left(\right.$ Table 5). Considering $A W C_{(F E)}$, significant differences 315 were only observed for the fixed floors beyond $200 \mathrm{~cm}$ depth. Considering the soil volume 316 until the bedrock depth, SAWC values did not differ significantly regarding the PTF used to 317 calculate the AWC coef $(\mathrm{FE})$. Result was the same considering the rooted volume, or the volume 318 until 300- and 200-centimeters depth. However, result differed for the surface material AWC: 319 significant differences were found between AWC values calculated from the local PTF, and 320 AWC values calculated from the Almajou 2008 PTF (Table 6).

321 Table 5: maximum, minimum and mean values for all the SAWC calculation. $N=100$

\begin{tabular}{lllcccc} 
Soil volume & AWCcoef $_{(\mathrm{FE})}$ & AWCcoef $_{(\mathrm{CF})}$ & Mean & Standard & Minimum & Maximum \\
& & & $(\mathbf{m m})$ & deviation & $(\mathbf{m m})$ & $(\mathbf{m m})$ \\
\hline $\mathrm{AWC}_{(\mathrm{Bedrock})}$ & Local & $\mathrm{AWC}_{(\text {Total) }}$ & 227.6 & 117.2 & 46.4 & 547.0
\end{tabular}




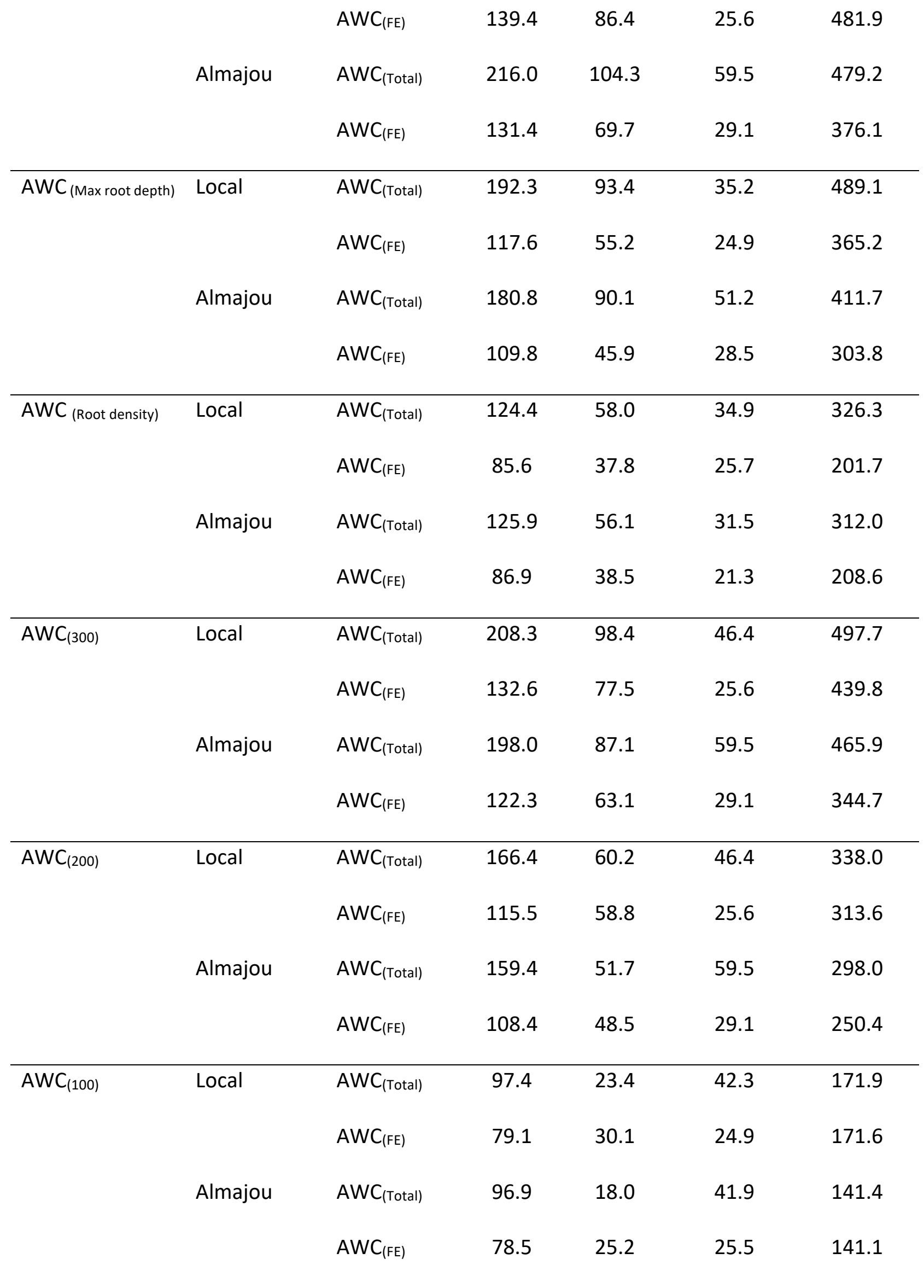




\begin{tabular}{lllcccc}
\hline $\mathrm{AWC}_{(50)}$ & Local & $\mathrm{AWC}_{(\text {Total }}$ & 51.7 & 10.7 & 26.1 & 82.3 \\
& $\mathrm{AWC}_{(\mathrm{FE})}$ & 46.1 & 13.3 & 18.7 & 81.9 \\
& Almajou & $\mathrm{AWC}_{(\text {Total })}$ & 55.9 & 8.0 & 26.3 & 71.4 \\
& $\mathrm{AWC}_{(\mathrm{FE})}$ & 50.3 & 11.4 & 18.9 & 71.1
\end{tabular}

322

323 Table 6: effect of the PTF and coarse fraction parameters on SAWC calculation for the 7 soil

324 volumes, using student test. $N=100 . N S=$ non-significant difference; significant difference at 325 the $0.05\left({ }^{*}\right) ; 0.01\left(^{* *}\right)$ and $0.001\left(^{* * *}\right)$ thresholds.

326

PTF effect Coarse fraction effect

\begin{tabular}{lcc} 
& Almajou Vs local PTF & $\mathrm{AWC}_{(\mathrm{FE}) \mathrm{Vs}} \mathrm{AWC}_{\text {(Total) }}$ \\
\cline { 2 - 3 } $\mathrm{AWC}_{(\text {Bedrock) }}$ & $\mathrm{NS}$ & $* * *$ \\
$\mathrm{AWC}_{\text {(Max root depth) }}$ & $\mathrm{NS}$ & $* * *$ \\
$\mathrm{AWC}_{(\text {Root density) }}$ & $\mathrm{NS}$ & $* *$ \\
$\mathrm{AWC}_{(300)}$ & $\mathrm{NS}$ & $* * *$ \\
$\mathrm{AWC}_{(200)}$ & $\mathrm{NS}$ & $* * *$ \\
$\mathrm{AWC}_{(100)}$ & $*$ & $* *$ \\
$\mathrm{AWC}_{(50)}$ & $* *$ & $* *$ \\
\hline
\end{tabular}

327

$328 \quad 4.5$ Relation with tree growth

329 Site fertility index, measured by $\mathrm{H}_{50}$ showed a mean of 35.4 meters high and a standard

330 deviation of 3.6. The most fertile plot reached a $\mathrm{H}_{50}$ of $44.6 \mathrm{~m}$ while the lowest fertility index

331 was $26.8 \mathrm{~m}$. 
Table 7: Spearman's correlation coefficients between the fertility index $\left(\mathrm{H}_{50}\right)$ and SAWC 333 calculated for the 7 soil volumes, including $A W C_{(\mathrm{CF})}\left(\mathrm{AWC}_{(\text {(Total) }}\right)$ or excluding it $\left(\mathrm{AWC} \mathrm{C}_{(\mathrm{FE})}\right)$, and 334 using the local PTF or Almajou PTF for AWCCoef $f_{(F E)}$ estimation. N=100. NS= non-significant 335 difference; significant difference at the $0.05\left({ }^{*}\right) ; 0.01\left(^{* *}\right)$ and $0.001\left(^{* * *}\right)$ thresholds.

\section{AWCcoef $_{(\mathrm{FE})}$}

\section{SAWC $\quad$ AWCcoef $_{(\mathrm{CF})}$ Almajou PTF Local PTF}

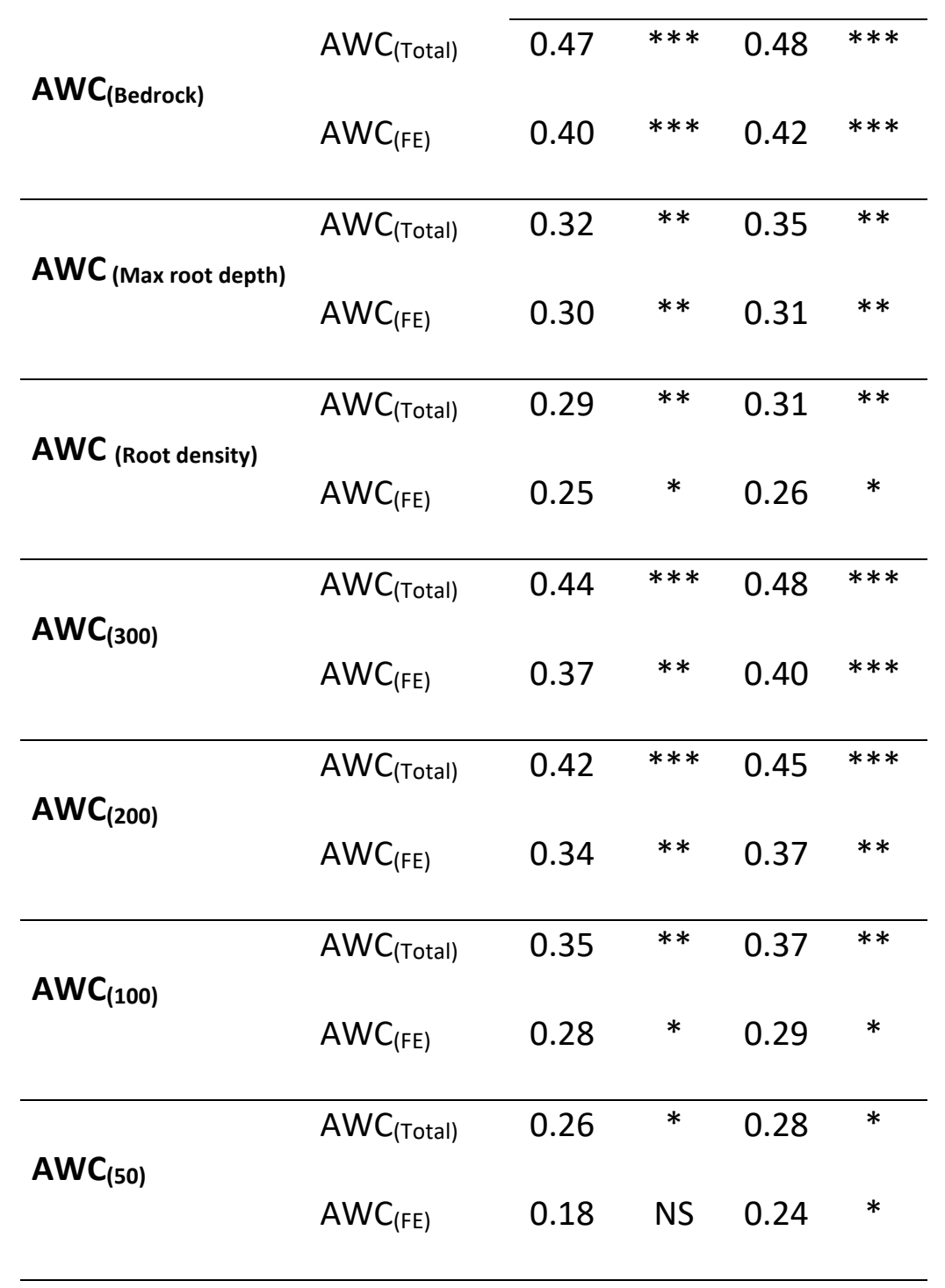

337 SAWC correlated significantly and positively with $\mathrm{H}_{50}$ whatever the considered soil volume 338 except for $A W C_{(50)}$. The best correlation coefficients were found for the greatest volumes of 339 soil without including the rooting effect $\left(A W C_{(B \text { edrock) }}, A W C_{(300)}\right.$ and $\left.A W C_{(200)}\right)$. Whatever the 
considered material, SAWC showed better correlation coefficient with $\mathrm{H}_{50}$ when it included

341 the $A W C_{(C F)}$. The effect of the chosen PTF for estimating the $A W C_{(F E)}$ did not alter the

342 relationship between SAWC and $\mathrm{H}_{50}$ : correlation coefficients were not significantly different.

\section{Discussion}

\subsection{Fine earth water retention}

The forest soils considered for the present study showed relative homogeneous sandy texture, high organic matter content. Such soil properties induced specific water retention behavior for the fine earth that were found to be very hardly predicted by using Almajou PTF. Indeed, while the Almajou PTF predicted homogeneous AWCCoef $_{(\mathrm{FE})}$, the coefficients based on the measured values showed higher variability, especially for the surface horizons.

Texture, as an only factor, might not be able to predict water retention for the studied soils. It seems that organic matter content may play an important role. Indeed, such relationship was partly found by using the continue local PTF. However, even if the relationship was statistically significant, it only allowed to predict $23 \%$ of the measured water retention variability. This lack of performance can be explained by the low number of samples used in this study (35) combined with a low range of water retention properties $\left(\mathrm{W}_{(\mathrm{FC})}, \mathrm{W}_{(\mathrm{WP})}\right)$ in comparison to other studies (ref).

Anyway, the fine earth retention seems not to impact less the variation of SAWC than other factors. As an explanation, the volume of fine earth has a very homogeneous soil texture. Furthermore, it is smaller than usually measured due to the richness in coarse fragments, and the increase of coarse fragment with depth result in a decrease of fine earth AWC impact. As a conclusion, the increase of variations of other AWC components than fine earth may explain this weak importance. However, it should be tried in more texture contrasted pedological context. It is also worth noting that recommended PTF failed to represent the fine earth 
retention variability and that the local PTF stress the negative impact of organic matter on the

365

366

367

368

wilting point, which, to our knowledge have never been encountered in studies dealing with agricultural soils. This re-enforce the need of specific PTF for forest soils.

\subsection{Retention of coarse fragment}

The water retention capacity of coarse fragment based on measurements was found important to take into account for explaining tree growth. The correlation coefficients raised significantly whatever the considered soil volume with however greater differences when deeper layers were considered. It is explained by the importance of coarse fragment, especially in the saprolite zone, but also to the substantial water retention of some of the pebbles.

Indeed, we measured AWCcoef $_{(\mathrm{CF})}$ varying between 0.11 and 1.21 depending on the rock fragment lithology. This is consistent with previous studies (Tetegan et al., 2011; Parajuli et al., 2017). Parajuli et al., 2017 showed that the water retention capacity of sandstones fragment was linked to the sample porosity. Tetegan et al. studied the water retention capacities of different types of sedimentary rocks. They found that the $A W C_{\text {(CF) }}$ depends on the rock fragment bulk density, with the higher $\mathrm{AWC}_{\mathrm{W}} \mathrm{f}_{(\mathrm{CF})}$ for bulk density varying between 1.5 and 1.8. The results of the present study for $A_{W C}$ coef $_{(C F)}$ values were very similar, even if the lithologic nature of the studied samples was very different. Considering the studied soils, the $A W C_{(C F)}$ represented $39 \%$ of the $A W C_{\text {(Total) }}$ for the $A W C_{\text {(Bedrock) }}$ and $31 \%$ for the $A W C_{(200)}$. We recommend that water retention of coarse fragment could be also accounted for. The variability shown in this study suggest that PTF should also be built for coarse fraction, and especially for the weathered rock fragment showing a low bulk density and high porosity. Finally, this result also underlined the crucial importance of a precise assessment of the coarse 
fraction volume within the soil profile. A $2 \mathrm{~cm}$ - sieving and weighing performed in the field appeared to be a progress from classical visual estimations from the profile wall.

Soil volume seems to be the main driver of SAWC in our study area. We showed that for Douglas-fir fertility index, the best correlation coefficients were obtained with SAWC

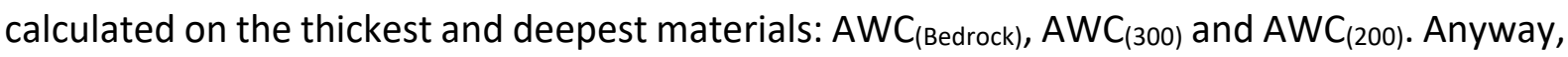
with correlation coefficients quite similar than $A W C_{(B e d r o c k)} A W C_{(200)}$ seemed to be deep and thick enough for accounting for the soil impact on the tree growth. This might mean that the critical AWC layer for tree fertility was not the global and potentially rooted saprolite zone, but a thinner volume of material that concentrated the higher root density (Brantley et al., 2017). In this way, the SAWCs taking into account direct observations of rooting depths (AWC (Max root depth), $A W C_{(\text {Root density) }}$ ) would have been theoretically the best methods for assessing SAWC. Indeed, root distribution is like a map of were water is most likely to be present during the growing season (Brantley et al., 2017). Curt et al., 1998 proposed a typology for the rootsystem architecture of Douglas-fir that was strongly correlated with Douglas-fir fertility index $402\left(\mathrm{H}_{25}\right)$. However, it was not the case for the present study. The correlation coefficients with $\mathrm{H}_{50}$ were lower for the SAWC weighted on the root density than for SAWC based on fixed floor depth. This can be explained by the difficulty in observing functional roots that are very thin 405 (diameter $<1 \mathrm{~mm}$ ) and by the omission of mycorrhizal effect.

Finally, the lower correlation coefficients were found for the surface material $A W C_{(100)}$ and $A W C_{(50)}$. Such material seemed to be not thick and deep enough to precisely characterize the SAWC potential for a given site. This result questions the common field method for SAWC assessment that used manual auger to probe the soil with a very limited depth. 
411 The SAWC-tree growth relation was found significative with SAWC explaining at best $23 \%$ of

412 the $\mathrm{H}_{50}$ variability. Many studies explored the relationships between tree growth and SAWC.

413 Piedallu et al. (2011) showed that SAWC calculated by using manual auger, Almajou PTF for

414 estimating $A W C_{(F E)}$, and without including the coarse fraction AWC could explained at most 12

$415 \%$ of the fertility index of Fagus sylvatica, Picea Abies and Quercus Petraea. Curt et al., (2001)

416 showed that SAWC explained $29 \%$ of Douglas-fir growth in the Limousin (French Massif

417 Central). For this study, SAWC was calculated on 1-meter depth pit using by the "texture

418 method" (Baize \& Jabiol, 1995), and Douglas-fir growth was estimated at the reference age of

41925 years. This stronger relationship for Curt et al. (2001) can be explained by a more

420 homogeneous climate and geology of the studied area than ours. Indeed, for the Haut-

421 Languedoc area, the climatic confluence situation and the geological heterogeneity induced

422 very complex interactions between the Douglas-fir growth factors. Climate variables such as

423 an early vegetative season water deficit (Sergent et al., 2012) and other factors such as

424 chemical fertility, former land use (Curt et al., 2001), or genetic origin of Douglas-fir trees

425 (Bansal et al., 2015) may also play an important role. SAWC appeared as a complementary

426 factor, but can be more useful when the first-order factors such as climate remain weakly

427 variable.

6. Conclusion

SAWC concept which was created for agricultural soils requires specific adaptations when it is

430 estimated for forest soils. The present study pointed three possible improvements for forest

SAWC assessment: 1) the development of specific PTF for forest soils, integrating texture and organic matter content as explanatory factors for fine earth water retention properties, 2) the integration of the coarse fraction AWC for SAWC calculation and thus, the development of 
assessment. This last point appears to be the most difficult to practically take into account in usual field sampling devices, because the digging of such a soil volume is expansive. Thus, the

437 modelling of the total soil thickness by using available surface and subsurface indicators could 438 be a crucial issue for forest soil AWC assessment.

\section{Acknowledgement}

440 We are grateful to the LIFE FORECCAsT project (LIFE15 CCA/FR/000021) who supported and 441 managed this work. We gratefully thank Jérôme Gouin (GeSolEau) for the soil profile description 442 and sampling, Evrard Gutkin for the soil pit digging and filling. This study would not be possible 443 without the help of the agents of the CRPF Occitanie and without the agreement of the forest 444 owners.

\section{References}

446 Al Majou, H., Bruand, A., Duval, O., 2008. The use of in situ volumetric water content at field 447 capacity to improve the prediction of soil water retention properties. Canadian Journal of Soil 448 Science 88, 533-541.

449 Angelier, A., 2006. Guide des sylvicultures pour le Douglas : de nouvelles courbes de fertilité 450 adaptées. Rendez-vous techniques. Office national des forêts 11, 7-12.

451 Baize, D., Jabiol, B., 1995. Guide pour la description des sols. INRA, Paris.

452 Bansal, Harrington, C., Gould, P., St Clair, J.B., 2015. Climate-related genetic variation in drought453 resistance of Douglas-fir (Pseudotsuga menziesii). Global Change Biology, 21(2),947-58. doi: $454 \quad 10.1111 /$ gcb.12719.

455 Breda, N., Huc, R., Granier, A., Dreyer, E., 2006. Temperate forest trees and stands under severe 456 drought: a review of ecophysiological responses, adaptation processes and long-term 457 consequences. Annals of Forest Science 63, 625-644. 

and bulk density of clods to generate water retention curves. Soil Use and Management 19, 232-

461 Chen, H.Y.H., Krestov, P.V., Klinka, K., 2002. Trembling aspen site index in relation to 462 environmental measures of site quality at two spatial scales. Canadian Journal of Forest Research -Revue Canadienne De Recherche Forestiere 32, 112-119.

464 Cousin, I., Nicoullaud, B., Coutadeur, C., 2003. Influence of rock fragments on the water retention 465 and water percolation in a calcareous soil. Catena 53, 97-114.

466 Curt, T., Bouchaud, M., Agrech, G., 2001. Predicting site index of Douglas-Fir plantations from 467 ecological variables in the Massif Central area of France. Forest Ecology and Management 149, 468 61-74.

469 Curt, T., Bouchaud, M., Lucot, E., Bardonnet, C., Bouquet, F., 1998. Influence des conditions 470 géopédologiques sur le système racinaire et la croissance en hauteur du Douglas dans les monts 471 du Beaujolais. Ingénieries - E A T, IRSTEA, 29 - 46.

472 Dominati, E., Mackay, A., Green, S., Patterson, M., 2014. A soil change-based methodology for the 473 quantification and valuation of ecosystem services from agro-ecosystems: a case study of pastoral 474 agriculture in New Zealand. Ecological Economics. Econ. 100, 119-129.

475 Graham, R. C., Rossi, A. M., Hubbert, K. R., 2010. Rock to regolith conversion: producing hospitable 476 substrates for terrestrial ecosystems, GSA Today 20, 4-9.

477 Granier, A., Bréda, N., Biron, P., Villette, S., 1999. A lumped water balance model to evaluate 478 duration and intensity of drought constraints in forest stands. Ecological Modelling, 116, 269-283. 479 Infosol, 2018. Donesol version 3.7. Dictionnaire de données. GISSOL, Orléans, 492 pp 480 Jamagne, M., Betremieux, R., Begon, J.C., Mori, A., 1977. Quelques données sur la variabilité dans 481 le milieu naturel de la réserve en eau des sols. agro - INRA 127, 627-641. 
482 Lebourgeois, F., Bréda, N., Ulrich, E., Granier, A., 2005. Climate-tree-growth relationships of 483 European beech (Fagus sylvatica L.) in the French Permanent Plot Network (RENECOFOR). Trees 484 Structure and Function 19, 385-401.

485 Littke K., Zabowski D., Turnblom E., Harrison R., 2018. Estimating shallow soil available water 486 supply for Douglas-fir forests of the coastal Pacific Northwest: climate change impacts. Canadian 487 Journal of Forest Research, 48(4), 421-430. https://doi.org/10.1139/cjfr-2017-0385

488 Parajuli K., Sadeghi M., Jones S.B., 2017. A binary mixing model for characterizing stony-soil water 489 retention. Agricultural and Forest Meteorology 1-8, 244-245.

490 Piedallu C., Gégout J.-C., Bruand A., Seynave I., 2011. Mapping soil water holding capacity over 491 large areas to predict potential production of forest stands. Geoderma, 160(3): 355-366.

492 Piedallu, C., Pousse, N., Bruand, A., Dietz, L., Fiquepron, J., 2018. Estimer le réservoir en eau des 493 sols. Quelles fonctions de pédotransfert le forestier doit-il utiliser ? Forêt-entreprise , 242, 28-32. 494 Sergent, A. S., Rozenberg, P., Bréda, N., 2012. Douglas-fir is vulnerable to exceptional and 495 recurrent drought episodes and recovers less well on less fertile sites. Annals of Forest Science 71, 496 697-708. DOI 10.1007/s13595-012-0220-5.

497 Seynave, I., Gégout, J.-C., Hervé, J.-C., Dhôte, J.-F., Drapier, J., Bruno, É., Dumé, G., 2005. Picea 498 abies site index prediction by environmental factors and understorey vegetation: a two-scale 499 approach based on survey databases. Canadian Journal of Forest Research, 35(7), 1669-1678. 500 doi:10.1139/x05-088

501 Steiger, J.H., 1980. Tests for comparing elements of a correlation matrix, Psychological 502 Bulletin, 87, 245-251.

503 Veihmayer, F.J., Hendrickson, A.H., 1927. Soil moisture conditions in relation to plant growth. 504 Plant Physiology, Lancaster, 2, 71-82.

505 Vincke, C., Delvaux, B., 2005. Porosity and available water of temporarily waterlogged soils in 506 a Quercus robur (L.) declining stand. Plant and Soil 271, 189-203. 
507 Wösten, J.H.M., Pachepsky, Y.A., Rawls, W.J., 2001. Pedotransfer functions: bridging the gap 508 between available basic soil data and missing soil hydraulic characteristics. Journal of 509 Hydrology (Amsterdam) 251, 123-150. 